EXTENDED REPORT

\title{
Indomethacin lowers optic nerve oxygen tension and reduces the effect of carbonic anhydrase inhibition and carbon dioxide breathing
}

\author{
D B Pedersen, T Eysteinsson, E Stefánsson, J F Kiilgaard, M la Cour, K Bang, P K Jensen
}

Br J Ophthalmol 2004;88:1088-1091. doi: 10.1136/bjo.2003.041251

See end of article for authors' affiliations

.....................

Correspondence to: D B Pedersen, $M D$, Department of Ophthalmology, 2061, Rigshospitalet, Blegdamsvej 9,2100 Copenhagen Ǿ, Denmark; daniella@dadlnet.dk

Accepted for publication 3 January 2004
Background/aims: Prostaglandins are important in blood flow regulation. Carbon dioxide $\left(\mathrm{CO}_{2}\right)$ breathing and carbonic anhydrase inhibition increase the oxygen tension in the retina and optic nerve. To study the mechanism of this effect and the role of cyclo-oxygenase in the regulation of optic nerve oxygen tension $\left(\mathrm{ONPO}_{2}\right)$, the authors investigated how indomethacin affects $\mathrm{ONPO}_{2}$ and the $\mathrm{ONPO}_{2}$ increases caused by $\mathrm{CO}_{2}$ breathing and carbonic anhydrase inhibition in the pig.

Methods: Optic nerve oxygen tension was measured in 11 pigs with a polarographic oxygen electrode. The tip of the electrode was placed $0.5 \mathrm{~mm}$ above the optic disc. The effects of indomethacin, $\mathrm{CO}_{2}$ breathing (3\%) before and after indomethacin treatment, and carbonic anhydrase inhibition with or without indomethacin treatment were investigated.

Results: Administration of $300 \mathrm{mg}$ indomethacin decreased optic nerve oxygen tension significantly. Carbonic anhydrase inhibition and $\mathrm{CO}_{2}$ breathing increased $\mathrm{ONPO}_{2}$ significantly. After indomethacin had been given, the rise in $\mathrm{ONPO}_{2}$ caused by $\mathrm{CO}_{2}$ breathing and carbonic anhydrase inhibition was significantly reduced.

Conclusion: Systemic administration of indomethacin decreases the optic nerve oxygen tension; this is probably the result of decreased blood flow through vasoconstriction of vessels in the optic nerve. Additionally, indomethacin diminishes the $\mathrm{ONPO}_{2}$ increasing effect of $\mathrm{CO}_{2}$ breathing and carbonic anhydrase inhibition, thus affecting the reactivity of vessels in the optic nerve.
$\mathrm{P}$ rostaglandins are important in regulating blood flow in skeletal muscle, stomach, kidney, brain, and retina. ${ }^{1}$ In the retina of miniature pigs, prostaglandin $E_{1}$ induces vasodilatation while indomethacin, blocking prostaglandin synthesis, causes vasoconstriction and diminishes the vasodilatory effect of hypoxia and hypercapnia. ${ }^{2}$ We investigated the role of prostaglandins in regulating optic nerve oxygen tension $\left(\mathrm{ONPO}_{2}\right)$ in steady state, during hypercapnia, and during carbonic anhydrase inhibition.

Systemic carbonic anhydrase inhibition induces vasodilatation and increases blood flow in the central nervous system $^{34}$ including the retina ${ }^{5}$ and choroid. ${ }^{6}$ Carbonic anhydrase inhibitors (CAIs) elevate $\mathrm{ONPO}_{2}$ in pigs ${ }^{7}$ but the mechanism of action is not known. Systemic administration of CAI causes carbon dioxide $\left(\mathrm{CO}_{2}\right)$ accumulation in blood and tissue, ${ }^{8}$ known to increase cerebral blood flow. ${ }^{9}$ Additionally $\mathrm{CO}_{2}$ breathing causes a similar increase in $\mathrm{ONPO}_{2}$ and arterial $\mathrm{PCO}_{2}$ as do CAIs. ${ }^{7}$ Therefore, it is likely that CAI works through $\mathrm{CO}_{2}$ to increase $\mathrm{ONPO}_{2}$.

The nitric oxide (NO) pathways probably have an important role in hypercapnic vasodilatation, ${ }^{10}$ but it is debatable whether prostaglandins are involved in this process. $^{21-14}$ We investigated if blocking the synthesis of prostaglandins affects baseline $\mathrm{ONPO}_{2}$ and the $\mathrm{ONPO}_{2}$ increases caused by $\mathrm{CO}_{2}$ and carbonic anhydrase inhibition.

\section{MATERIALS AND METHODS \\ Materials}

Eleven pigs (Danish Landrace), weighing 28-30 kg were used. Their treatment was supervised by a veterinarian nurse and followed the ARVO resolution for the use of animals in ophthalmic and vision research. Permission for using the pigs was granted by the Danish board for surveillance of the use of experimental animals (Danish Animal Experiments Inspectorate).

Dorzolamide $\mathrm{HCl}$ was obtained from Merck, Sharp \& Dohme, Glostrup, Denmark; $500 \mathrm{mg}$ was dissolved as a 3\% solution in $100 \mathrm{mM}$ citrate buffer, $\mathrm{pH}$ 5.6. Indomethacin (Bie \& Berntsen, Copenhagen, Denmark) was dissolved in isotonic saline $(6 \mathrm{mg} / \mathrm{ml})$ by stirring the solution for 1 hour. Breathing of $3 \% \mathrm{CO}_{2}$ was performed by adding $\mathrm{CO}_{2}$ (AGA, Copenhagen, Denmark) to the air, making inspiratory air contain 3\% $\mathrm{CO}_{2}$, decreasing nitrogen correspondingly

\section{Anaesthesia and animal preparation}

Anaesthesia and animal preparation was performed as previously described. ${ }^{15}$

\section{Oxygen tension measurements}

The optic nerve oxygen tension was measured with a polarographic oxygen electrode with an internal $\mathrm{Ag} / \mathrm{AgCl}$ reference electrode. The electrode was placed over the optic nerve in the pig as previously described. ${ }^{15}$

\section{Experimental protocol}

Arterial blood samples were drawn from the catheter in the femoral artery and analysed for arterial oxygen tension $\left(\mathrm{aPO}_{2}\right)$, arterial carbon dioxide tension $\left(\mathrm{aPCO}_{2}\right)$, and arterial $\mathrm{pH}(\mathrm{apH})$ using an ABL 605 blood gas analyser (Radiometer, Copenhagen, Denmark).

Normal values for $\mathrm{aPO}_{2}(10-14 \mathrm{kPa}), \mathrm{aPCO}_{2}(5.5-7.5 \mathrm{kPa})$, and apH (7.38-7.42) were ensured by adjusting the respirator.

Abbreviations: $\mathrm{aPCO}_{2}$, arterial $\mathrm{PCO}_{2} ; \mathrm{apH}$, arterial $\mathrm{pH} ; \mathrm{aPO}_{2}$, arterial $\mathrm{PO}_{2}$; CAls, carbonic anhydrase inhibitors; $\mathrm{HR}$, heart rate; $\mathrm{MAP}$, mean arterial pressure; $\mathrm{NO}$, nitric oxide; $\mathrm{ONPO}_{2}$, optic nerve oxygen tension 


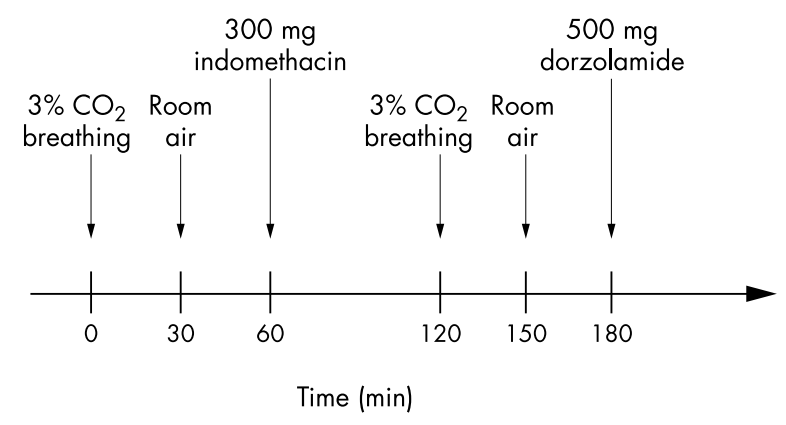

Figure 1 The course of the experiment. Initially $3 \% \mathrm{CO}_{2}$ breathing is induced (control; $n=4$ ); 30 minutes later, the breathing air is changed back to room air. After having reached baseline, $300 \mathrm{mg}$ indomethacin is injected intravenously $(n=5)$. One hour later, $3 \% \mathrm{CO}_{2}$ breathing is started again (indomethacin treated pigs; $n=4$ ). After 30 minutes of room air, $500 \mathrm{mg}$ dorzolamide is injected $(n=5)$.

Initially a stable oxygen recording in the vitreous was obtained. Then the pig was given $100 \%$ oxygen in the inspiratory air ensuring that the oxygen electrode worked satisfactorily. Following this the pig was ventilated with atmospheric air, except when $\mathrm{CO}_{2}$ breathing was performed.

Figure 1 shows the course of the experiment for the pigs given indomethacin $(n=5)$. The control pigs $(n=6)$ were given $500 \mathrm{mg}$ dorzolamide.

The mean total duration of the experiments was 6 hours and 15 (SD 66) minutes $(\mathrm{n}=11)$. The oxygen electrode drift was less than $-0.1 \mathrm{kPa} / \mathrm{h}$.

\section{Data processing}

$\mathrm{ONPO}_{2}$, mean arterial pressure (MAP) and heart rate (HR) values (a window of 15 seconds of the recording was averaged with the Axoscope program) for baseline and time points after injection of the study drugs were used for all the calculations.

The mean and standard deviation of $\mathrm{ONPO}_{2}$, apH, $\mathrm{aPCO}_{2}$, $\mathrm{aPO}_{2}, \mathrm{MAP}$, and HR were calculated and presented in table 1.

Differences in the parameters before and after drug injections in each pig were tested for significance using Student's paired two tailed $t$ test (table 1). Differences in the $\mathrm{ONPO}_{2}$ changes between groups were tested for significance using Student's unpaired two tailed $t$ test. A significance level of 0.05 was used.

Graphic presentations of the tracings were made in SigmaPlot 2001 for Windows (Version 6.00 SPSS Inc, Chicago, IL, USA).

\section{RESULTS}

\section{The effect of indomethacin on $\mathrm{ONPO}_{2}$}

Before injection of indomethacin, baseline optic nerve oxygen tension was $2.96(0.59) \mathrm{kPa}(\mathrm{n}=5)$. This was significantly decreased by $-1.22(0.43) \mathrm{kPa}(\mathrm{p}=0.002) \quad \mathrm{l}$ hour after administration of $300 \mathrm{mg}$ indomethacin (table $\mathrm{l}$ and fig 2A). All other parameters had not changed significantly 60 minutes after the injection (table 1).

\section{The effect of $\mathrm{CO}_{2}$ breathing on $\mathrm{ONPO}_{2}$ before and after indomethacin treatment}

$\mathrm{ONPO}_{2}$ was significantly increased by $0.66(0.23) \mathrm{kPa}(\mathrm{n}=4$, $\mathrm{p}=0.002) 30$ minutes after the start of $3 \% \mathrm{CO}_{2}$ breathing (table 1, figs $2 \mathrm{~B}$ and 3 ). After indomethacin administration, $3 \% \mathrm{CO}_{2}$ breathing caused an insignificant increase in $\mathrm{ONPO}_{2}$ $(p=0.27) \quad$ (table 1 , figs $2 \mathrm{~B}$ and 3$)$. This increase was significantly smaller than before administration of the drug $(\mathrm{p}=0.029)$ (fig 3). One experiment with $\mathrm{CO}_{2}$ breathing was excluded because of movement of the pig head; however, the measurements during the following injection of dorzolamide could be performed satisfactorily and was included.

\section{The effect of CAI on $\mathrm{ONPO}_{2}$ with and without indomethacin treatment}

Dorzolamide $500 \mathrm{mg}$ increased $\mathrm{ONPO}_{2}$ significantly by 0.73 (0.34) $\mathrm{kPa}(\mathrm{n}=6, \mathrm{p}=0.004)$ in the untreated pigs (table $\mathrm{l}$, figs $2 \mathrm{C}$ and 4 ). In the indomethacin treated pigs an intravenous injection of $500 \mathrm{mg}$ dorzolamide increased $\mathrm{ONPO}_{2}$ by $0.22(0.12) \mathrm{kPa}(\mathrm{n}=5, \mathrm{p}=0.015)$ (table $\mathrm{l}$, figs $2 \mathrm{C}$ and 4$)$. This was a significantly smaller increase than in the controls $(\mathrm{p}=0.013$ ) (fig 4$)$, despite similar changes in $\mathrm{apH}$ and $\mathrm{aPCO}_{2}$ in the animals (table 1).

\section{DISCUSSION}

In this study two new findings were done. Firstly, indomethacin injected intravenously decreased optic nerve oxygen tension. Secondly, the $\mathrm{ONPO}_{2}$ increasing effect of $\mathrm{CO}_{2}$ breathing and of carbonic anhydrase inhibition was reduced

Table 1 Optic nerve oxygen tension $\left(\mathrm{ONPO}_{2}\right)$, arterial $\mathrm{pH}(\mathrm{apH})$, arterial $\mathrm{PCO}_{2}\left(\mathrm{aPCO}_{2}\right)$, arterial $\mathrm{PO}_{2}\left(\mathrm{aPO}_{2}\right)$, mean arterial pressure (MAP), and heart rate (HR) before and at a time point after $\mathrm{CO}_{2}$ breathing, indomethacin injection, or dorzolamide injection. The chosen time points are 60 minutes after the injection of indomethacin and 30 minutes after beginning of $\mathrm{CO}_{2}$ breathing and carbonic anhydrase inhibition

\begin{tabular}{|c|c|c|c|c|c|}
\hline & \multirow{2}{*}{$\begin{array}{l}300 \mathrm{mg} \text { indomethacin iv } \\
(\mathrm{n}=5)\end{array}$} & \multicolumn{2}{|c|}{$3 \% \mathrm{CO}_{2}$ breathing } & \multicolumn{2}{|c|}{$500 \mathrm{mg}$ dorzolamide iv } \\
\hline & & $\begin{array}{l}\text { Controls } \\
(n=4)\end{array}$ & $\begin{array}{l}\text { Indomethacin treated } \\
(\mathrm{n}=4)\end{array}$ & $\begin{array}{l}\text { Controls } \\
(n=6)\end{array}$ & $\begin{array}{l}\text { Indomethacin treated } \\
(n=5)\end{array}$ \\
\hline $\mathrm{ONPO}_{2}$ (baseline) (kPa) & $2.96(0.56)$ & $2.92(0.52)$ & $1.81(0.39) \dagger$ & $3.63(1.00)$ & $1.86(0.54) \dagger$ \\
\hline$\triangle \mathrm{ONPO}_{2}$ (time point) (kPa) & $-1.22(0.43)^{*}$ & $0.66(0.23)^{*}$ & $0.17(0.25) \dagger$ & $0.73(0.34)^{*}$ & $0.22(0.12)^{*} \dagger$ \\
\hline apH (baseline) & $7.39(0.01)$ & $7.40(0.01)$ & $7.41(0.01)$ & $7.41(0.01)$ & $7.42(0.01)$ \\
\hline $\mathrm{apH}$ (time point) & $7.40(0.02)$ & $7.31(0.02)^{*}$ & $7.32(0.02)^{*}$ & $7.33(0.02)^{*}$ & $7.35(0.02)^{*}$ \\
\hline $\mathrm{aPCO}_{2}$ (baseline) $(\mathrm{kPa})$ & $7.7(0.4)$ & $7.1(0.4)$ & $7.2(0.5)$ & $7.0(0.5)$ & $7.2(0.3)$ \\
\hline $\mathrm{aPCO}_{2}$ (time point) $(\mathrm{kPa})$ & $7.4(0.7)$ & $9.1(0.6)^{*}$ & $9.1(0.5)^{*}$ & $8.2(0.5)^{\star}$ & $8.3(0.3)^{*}$ \\
\hline $\mathrm{aPO}_{2}$ (baseline) $(\mathrm{kPa})$ & $12.1(0.9)$ & $11.7(1.0)$ & $13.3(0.8)$ & $11.2(1.0)$ & $13.1(1.6)$ \\
\hline $\mathrm{aPO}_{2}$ (time point) (kPa) & $12.8(1.4)$ & $11.0(1.7)$ & $12.6(2.7)$ & $11.0(1.0)$ & $12.9(1.2)$ \\
\hline MAP (baseline) (mmHg) & $109(12)$ & $112(18)$ & $121(18)$ & $99(18)$ & $119(14)$ \\
\hline MAP (time point) $\mathrm{mmHg}$ ) & $124(17)$ & $112(13)$ & $116(12)$ & $95(22)$ & $107(13)$ \\
\hline HR (baseline) & $77(5)$ & $76(6)$ & $75(10)$ & $83(14)$ & $78(7)$ \\
\hline HR (time point) & $75(8)$ & $72(7)$ & 76 (16) & $90(16)$ & 77 (15) \\
\hline
\end{tabular}

Data are presented as mean (SD).

${ }^{*}$ Indicates that the values at the time point after beginning of the manipulation are significantly different from baseline ( $p<0.05$, Student's paired $t$ test). tIndicates that the values in the indomethacin treated pigs are significantly different from the values in the corresponding control pigs ( $p<0.05$, Student's unpaired $t$ test). 

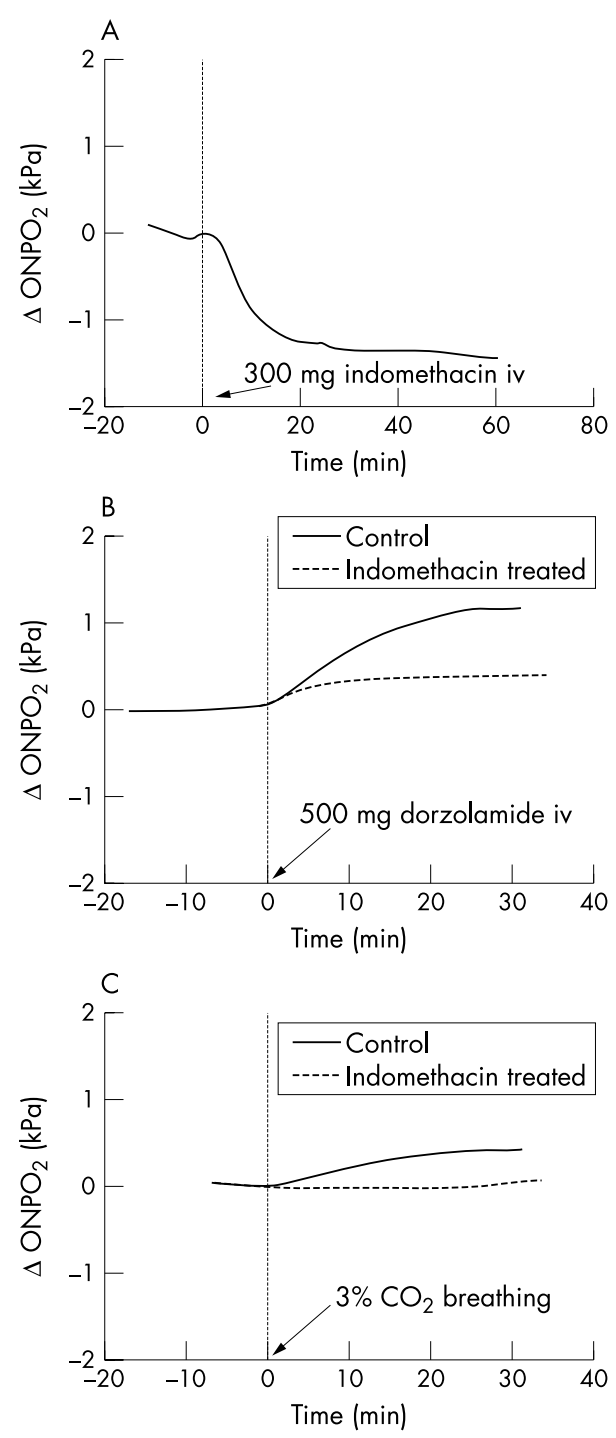

Figure 2 Recording of the delta optic nerve oxygen tension in $\mathrm{kPa}$ over time during different kinds of manipulations. Baseline $\triangle O N P \mathrm{O}_{2}$ (before the beginning of the manipulation) is calibrated to $0 \mathrm{kPa}$. (A) The effect of injection of $300 \mathrm{mg}$ indomethacin at time 0 . (B) The effect of $3 \% \mathrm{CO}_{2}$ breathing at time 0 before and after indomethacin treatment. (C) The effect of injection of $500 \mathrm{mg}$ dorzolamide at time 0 in indomethacin treated animals and in controls.

in indomethacin treated animals when compared with controls.

The indomethacin induced decrease in $\mathrm{ONPO}_{2}$ is probably caused by vasoconstriction and thereby decreased blood flow in the optic nerve. Indomethacin inhibits the production of prostaglandins. ${ }^{16}$ The fact that indomethacin decreases $\mathrm{ONPO}_{2}$ suggests that prostaglandins have a constant vasodilatory tonus on retinal vessels, as has NO. ${ }^{17}$ Myography studies have shown that derivatives of arachidonic acids such as prostaglandin $\mathrm{F}_{2 \alpha}$, prostaglandin $\mathrm{E}_{2}$, nd thromboxane ${ }_{2}$ have a vasoconstrictory tonus on calf retinal arterioles, whereas prostacyclin (prostaglandin $\mathrm{I}_{2}$ ) has a vasodilatory tonus. ${ }^{18}$ The same types of study found a weak contraction in human ciliary arteries induced by indomethacin. ${ }^{19}$ Our study indicates that the vasodilatory tonus of the prostaglandins on vessels in the optic nerve is more important than their vasoconstrictory tonus.

Perfusion with indomethacin of the eye of minipigs constricts retinal arterioles, ${ }^{20}$ but despite continuous perfusion of

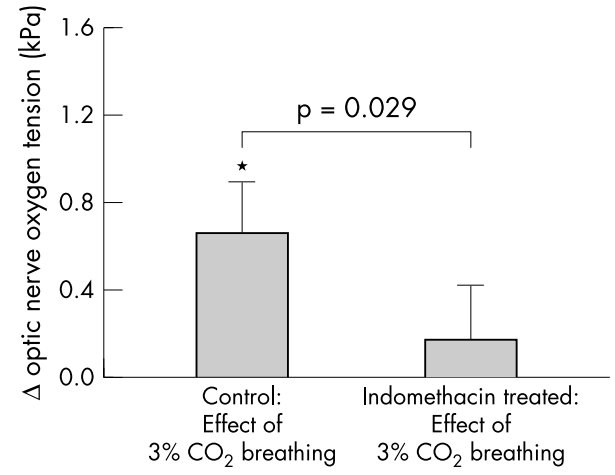

Figure 3 The increase in optic nerve oxygen tension 30 minutes after beginning of $3 \% \mathrm{CO}_{2}$ breathing (mean (SD)) in control pigs $(n=4)$ and indomethacin treated pigs $(n=4)$. *Indicates a significant increase (Student's paired $t$ test, $\mathrm{p}<0.05$ ). The $\Delta$ values are compared by using a Student's unpaired $t$ test.

indomethacin, this effect disappears after 10 minutes. In our experiments, however, the effect lasted the whole period of observation (maximum 70 minutes) (fig 2A). The blood flow decreasing effect of indomethacin lasts for at least $150 \mathrm{~min}$ utes in the human brain. ${ }^{21}$ Systemic administration of indomethacin also decreases cerebral blood flow in rabbits, ${ }^{1}$ rats, ${ }^{22}$ newborn pigs, ${ }^{23}{ }^{24}$ and humans. ${ }^{21}{ }^{25}$ However, Cuypers et al did not find this effect in the rabbits they examined. ${ }^{26}$

We found that indomethacin decreased the $\mathrm{ONPO}_{2}$ increasing effect of $\mathrm{CO}_{2}$. We interpret this to be caused by a reduced $\mathrm{CO}_{2}$ reactivity of optic nerve blood vessels. Similar findings have been reported for the cerebral vessels in rabbits $^{14}$ and humans. ${ }^{2125}$ However, others have not found any effect of indomethacin on cerebral vessel $\mathrm{CO}_{2}$ reactivity in cats ${ }^{12}$ and rabbits. ${ }^{26}$

In our experiments, indomethacin also decreased the effect of CAI on $\mathrm{ONPO}_{2}$. A similar effect of indomethacin on CAI reactivity has been reported in rat cerebral vessels. ${ }^{11}$ Since indomethacin reduced the $\mathrm{ONPO}_{2}$ increase induced by both $\mathrm{CO}_{2}$ breathing and carbonic anhydrase inhibition and since both of these manipulations cause $\mathrm{CO}_{2}$, accumulation it is likely that the effect of carbonic anhydrase inhibition on $\mathrm{ONPO}_{2}$ is caused by the effect of $\mathrm{CO}_{2}$ accumulation.

There are no qualitative differences between the effects of the different cyclo-oxygenase inhibitors ${ }^{27}$; therefore, other types of NSAID may also decrease the oxygen tension in the optic nerve. However, it has been shown that aspirin does not

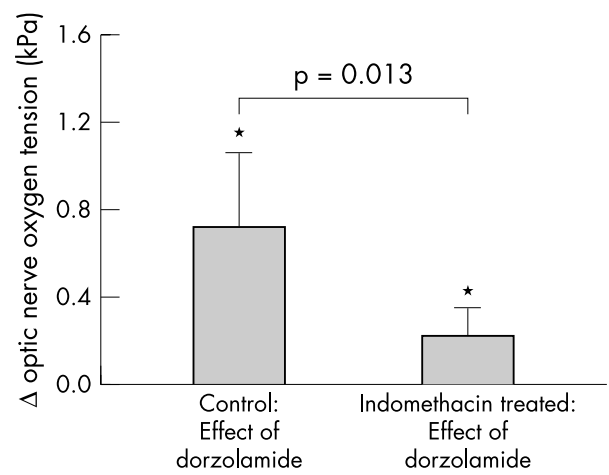

Figure 4 The increase in optic nerve oxygen tension 30 minutes after $500 \mathrm{mg}$ dorzolamide iv (mean (SD)) in control pigs $(\mathrm{n}=6)$ and indomethacin treated pigs $(n=5)$. *Indicates a significant increase (Student's paired $t$ test, $\mathrm{p}<0.05$ ). The $\Delta$ values are compared by using a Student's unpaired $t$ test. 
decrease cerebral blood flow in humans. ${ }^{21} 25$ Also diclofenac does not decrease the cerebral blood flow in rats while ibuprofen does. ${ }^{11}$ Ibuprofen decreases pial vessel diameter in newborn pigs but does not affect the $\mathrm{CO}_{2}$ reactivity of these vessels. ${ }^{24}$ Indomethacin may therefore change the vessel reactivity through affecting other processes than the prostaglandin synthesis, ${ }^{27}$ but it may also be a more potent drug in inhibiting cyclo-oxygenase. ${ }^{28}$ The inhibiting effect of indomethacin on $\mathrm{CO}_{2}$ reactivity in cerebral vessels have been reversed by directly adding prostaglandins. ${ }^{24}$ Thus, it is likely that prostaglandins at least facilitate $\mathrm{CO}_{2}$ induced vasodilation. $^{24}$

We have previously shown that measurements of the oxygen tension in the normal pig vitreous can be obtained using the $20 \mu \mathrm{m}$ oxygen electrodes, employed in the present study. ${ }^{75}$ The vitreous acts as a diffusion medium with very low metabolism and oxygen gradient (about $2 \mathrm{~mm} \mathrm{Hg}$ per $\mathrm{mm}$ in vitreous). Thus, the measurements in front of the optic nerve and retina are relatively insensitive to the exact location of the sensor. Also, the oxygen molecule diffuses freely from the retinal vessels to the retina and to the vitreous. Therefore, we interpret the oxygen measurements in the vitreous as reflecting the average oxygen concentration in the vitreal part of the retina and optic nerve head denoted optic nerve oxygen tension and retinal oxygen tension.

Intravenously injected indomethacin decreases $\mathrm{ONPO}_{2}$ in pigs. Also indomethacin diminishes the increase in $\mathrm{ONPO}_{2}$ induced by carbonic anhydrase inhibition and $\mathrm{CO}_{2}$ breathing, indicating that the regulation of the vessels is impaired. This may be relevant with regard to patients with ischaemic diseases in the retina and optic nerve treated with indomethacin or other NSAIDs, since not only may a vasoconstriction be happening but also the ischaemic areas of the tissues may lose the important vasodilatory effect of $\mathrm{CO}_{2}$. The effects of different kinds of NSAIDs have been investigated, and the results have been contradictory. ${ }^{11} 212425$ Further investigations are needed to clarify whether other NSAIDs have the same effect as indomethacin and also if the drugs orally or topically administered affect optic nerve oxygen tension.

\section{ACKNOWLEDGEMENTS}

The authors thank veterinary technician Mette Olesen, veterinary nurse Letty Klarskov and other staff at the Experimental Surgry Unit, Panum Institute, University of Copenhagen for their assistance with the handling of the experimental animals.

\section{Authors' affiliations}

D B Pedersen, J F Kiilgaard, M la Cour, P K Jensen, Department of Ophthalmology, Rigshospitalet, Copenhagen, Denmark

D B Pedersen, J F Kiilgaard, University of Copenhagen, Denmark T Eysteinsson, E Stefánsson, Department of Ophthalmology, University of Iceland, Reykjavik, Iceland

K Bang, Merck, Sharp \& Dohme, Glostrup, Denmark

Supported by University of Copenhagen, Værn om Synet, Denmark, MSD Inc, Denmark, University of Iceland Research Fund, and Helga Jónsdóttir and Sigurlioi Kristiánsson memorial Fund, Iceland.

\section{REFERENCES}

1 Bill A. Effects of indomethacin on regional blood flow in conscious rabbits - a microsphere study. Acta Physiol Scand 1979;105:437-42.

2 Pournaras C, Tsacopoulos M, Chapuis P. Studies on the role of prostaglandins in the regulation of retinal blood flow. Exp Eye Res 1978;26:687-97.

3 Vorstrup S, Henriksen L, Paulson OB. Effect of acetazolamide on cerebral blood flow and cerebral metabolic rate for oxygen. J Clin Invest 1984;74: 1634-9.

4 Hauge A, Nicolaysen G, Thoresen M. Acute effects of acetazolamide on cerebral blood flow in man. Acta Physiol Scand 1983;117:233-9.

5 Rassam SM, Patel V, Kohner EM. The effect of acetazolamide on the retinal circulation. Eye 1993;7(Pt 5):697-702.

6 Dallinger S, Bobr B, Findl O, et al. Effects of acetazolamide on choroidal blood flow. Stroke 1998;29:997-1001.

7 Stefánsson $\mathbf{E}$, Jensen PK, Eysteinsson T, et al. Optic nerve oxygen tension in pigs and the effect of carbonic anhydrase inhibitors. Invest Ophthalmol Vis Sci 1999;40:2756-61

8 Taki K, Hirahara K, Totoki T, et al. Retention of carbon dioxide in tissue following carbonic anhydrase inhibition in dogs. Clin Ther 1993;15:884-9.

9 Guyton AC. In: Wonsiewicz MJ, eds. Textbook of medical physiology, 8th ed. Philadelphia: WB Saunders, 1991:185-93.

10 Wang Q, Paulson OB, Lassen NA. Effect of nitric oxide blockade by NG-nitroL-arginine on cerebral blood flow response to changes in carbon dioxide tension. J Cereb Blood Flow Metab 1992;12:947-53.

11 Wang Q, Paulson OB, Lassen NA. Indomethacin abolishes cerebral blood flow increase in response to acetazolamide-induced extracellular acidosis: a mechanism for its effect on hypercapnia? J Cereb Blood Flow Metab 1993;13:724-7.

12 Busija DW, Heistad DD. Effects of indomethacin on cerebral blood flow during hypercapnia in cats. Am J Physiol 1983;244:H519-24.

13 Busija DW. Role of prostaglandins in the response of the cerebral circulation to carbon dioxide in conscious rabbits. J Cereb Blood Flow Metab 1983;3:376-80.

14 Csete K, Barzo P, Bodosi M, et al. Influence of nitrovasodilators and cyclooxygenase inhibitors on cerebral vasoreactivity in conscious rabbits. Eur J Pharmacol 2001;412:301-9.

15 Kiilgaard JF, Pedersen DB, Eysteinsson T, et al. Optic nerve oxygen tension: the effect of timolol and dorzolamide, Br J Ophthalmol 2004;88:276-9.

16 Vane JR. Inhibition of prostaglandin synthesis as a mechanism of action for aspirin-like drugs. Nat New Biol 1971;231:232-5.

17 Koss MC. Functional role of nitric oxide in regulation of ocular blood flow. Eur J Pharmacol 1999;374:161-74.

18 Nielsen PJ, Nyborg NC. Contractile and relaxing effects of arachidonic acid derivatives on isolated bovine retinal resistance arteries. Exp Eye Res 1990;50:305-11.

19 Nyborg NC, Nielsen PJ. The level of spontaneous myogenic tone in isolated human posterior ciliary arteries decreases with age. Exp Eye Res 1990;51:711-5.

20 Brazitikos PD, Pournaras CJ, Munoz JL, et al. Microinjection of L-lactate in the preretinal vitreous induces segmental vasodilation in the inner retina of miniature pigs. Invest Ophthalmol Vis Sci 1993;34:1744-52.

21 Markus HS, Vallance P, Brown MM. Differential effect of three cyclooxygenase inhibitors on human cerebral blood flow velocity and carbon dioxide reactivity. Stroke 1994;25:1760-4.

22 Dahlgren N, Nilsson B, Sakabe T, et al. The effect of indomethacin on cerebral blood flow and oxygen consumption in the rat at normal and increased carbon dioxide tensions. Acta Physiol Scand 1981;111:475-85.

23 Mirro R, Leffler CW, Armstead W, et al. Indomethacin restricts cerebral blood flow during pressure ventilation of newborn pigs. Pediatr Res 1988;24:59-62.

24 Wagerle LC, Degiulio PA. Indomethacin-sensitive $\mathrm{CO}_{2}$ reactivity of cerebral arterioles is restored by vasodilator prostaglandin. Am J Physiol 1994;266:H1332-8.

25 Eriksson S, Hagenfeldt L, Law D, et al. Effect of prostaglandin synthesis inhibitors on basal and carbon dioxide stimulated cerebral blood flow in man. Acta Physiol Scand 1983;117:203-11.

26 Cuypers J, Cuevas A, Duisberg R. Effect of indomethacin on $\mathrm{CO}_{2}$-induced hyperaemia $\left(\mathrm{CO}_{2}\right.$-response) in the rabbit brain. Neurochirurgia (Stuttg) 1978;21:62-6.

27 Flower RJ. Drugs which inhibit prostaglandin biosynthesis. Pharmacol Rev 1974;26:33-67.

28 Payan DG. In: Katzung BG, eds. Basic and clinical pharmacology, 5th ed. East Norwalk, Connecticut: Appleton \& Lange, 1992:491-512. 